\title{
Human Visual Acuity in Analysis of Intervention in the Landscape of Coxilha Rica/Brazil
}

\author{
Vivian Da Silva Celestino Reginato ${ }^{1}$ (), Samuel Abati2 (i) \\ ${ }^{1}$ Department of Civil Engineering, Federal University of Santa Catarina (UFSC), Florianopolis, Brazil \\ ${ }^{2}$ CGT Eletrosul Centrais Elétricas, Florianópolis, Brazil \\ Email: vivian.celestino@ufsc.br, sabati@eletrosul.gov.br
}

How to cite this paper: Reginato, V.D.S.C. and Abati, S. (2020) Human Visual Acuity in Analysis of Intervention in the Landscape of Coxilha Rica/Brazil. Journal of Geographic Information System, 12, 70-83. https://doi.org/10.4236/jgis.2020.122004

Received: February 17, 2020

Accepted: March 23, 2020

Published: March 26, 2020

Copyright $\odot 2020$ by author(s) and Scientific Research Publishing Inc. This work is licensed under the Creative Commons Attribution International License (CC BY 4.0).

http://creativecommons.org/licenses/by/4.0/ (c) (i) Open Access

\begin{abstract}
The Drovers' Paths are remnants of important land access roads from Rio Grande do Sul to São Paulo at the time of Colonial Brazil. They were built and used between the 18th and 20th centuries, particularly in the region of Coxilha Rica. The main objective of this research is to develop a method for decision-making applied to the territorial landscape management in the Coxilha Rica. The method consisted of generating criteria to map the visibility spot reached from the main selected points; define the human visual acuity, realize bibliographic research, use cartographic and historical documents, inter-views, as well as field surveys that enabled the identification, characterization and mapping of historical farms and drovers' paths. After data processing, the information was entered into the cartographic database; the data were cross-checked and analysis was made of the visibility of the surrounding farms and stone-walled corridors. Quality assessments showed that, with the visibility polygons, and through the use of cartographic tools, we could cross-check between different levels of information and analyze landscape intervention alternatives in order to minimize environmental impacts. When applying the method in the Coxilha Rica it was possible mapping the visibility polygon, taking human visual acuity into consideration, based on historical farms and stone-walled corridors; and making spatial analyses to explore alternatives to intervention (installation of power transmission systems) in order to preserve the scenic environment of the region. In the end, the decision was by does not construct the system.
\end{abstract}

\section{Keywords}

Territorial Management, Drovers' Path, Visibility Study, Human Visual Acuity 


\section{Introduction}

By the time of Colonial Brazil, around the 18th century, important land routes were built and used until the mid-20th century to transport mule trains and cattle for commercial supply purposes between Rio Grande do Sul and the gold mine region, passing through Sorocaba (São Paulo state) and Campos de Lages in Santa Catarina state. This period of cultural manifestation, which combined different customs and economic activities, was referred to as Tropeirismo ("Animal Drovers' Activity") [1].

Historical and cultural remnants of this period are present throughout a region called Coxilha Rica, and because of its unique features, the Institute of National Historical and Artistic Heritage (IPHAN) - a Brazilian federal agency linked to the Ministry of Culture, responsible for preserving the diversity of contributions of the different elements that make up the Brazilian society and its ecosystems showed concern for the preservation of these elements in the region, not only for Coxilha Rica's tourist potential, historical farms, old stone-walled corridors, local cuisine, and horseback riding fields, but also for its outstanding hydrological potential.

Coxilha Rica has some of the main rivers that form the springs of the Uruguay River, with large areas of fields and enclosed valleys that drain a large volume of water and offer high hydroelectric potential. IPHAN, concerned about the preservation of the scenic environment, and taking into account the significant number of hydroelectric projects under analysis, requested that the companies involved in the projects should work together to develop a method to minimize a negative impact on the area in the future. Such concern was relevant, not only because of environmental damage that could be caused, but also because of the visual impact resulting from the installation of transmission systems in the scenic environment.

For this reason, this research has become scientifically relevant, mainly for developing a support method, a tool and cartographic products for decisionmaking in territorial landscape management. In view of the need to preserve this important heritage, and in compliance with environmental constraints, historical research and other studies were started, aimed at minimizing possible visual impact on the power transmission system (to drain the energy generated by hydroelectric dams) on the landscape, caused by structures and cables for carrying electricity to the consuming centers.

Right at the beginning of the research work, there was a clear need to delimit the area of the polygons that were to be generated. For this purpose, specific studies were developed to estimate the human visual range and to delimit the coverage area of subsequent studies and applications.

The aim of this paper is to develop a method for decision-making applied to territorial landscape management. Particularly, the objectives are:

- To apply the method of human visual range for a definition of visibility polygons; 
- To generate visibility polygons for the region of Coxilha Rica;

- To generate thematic maps at different scales.

\section{Theoretical Background}

Studying a landscape, such as the landscape of a path used by animal, military, and human troops, requires understanding that this is a theoretical cultural construction made in the present about relationships and a society and an environment from the past [2].

Discussions and reflections concerning the landscape and the relationship between man and the environment were developed in the United States and gained emphasis in Europe. In the operational guidelines for implementation of the World Heritage Convention in 1999, UNESCO presented the idea of cultural landscape in more detail as: "Cultural landscapes represent the combined works of nature and of man [...]. They are illustrative of the evolution of human society and settlement over time, under the influence of the physical constraints and/or opportunities presented by their natural environment and of successive social, economic and cultural forces, both external and internal. They should be selected on the basis both of their outstanding universal value and of their representativity in terms of a clearly defined geo-cultural region and also for their capacity to illustrate the essential and distinct cultural elements of such regions [3]."

Herberts analyzed the Caminho das Tropas ("Drovers' Path") and the various structures that compose the landscape seen by drovers [4]. The author sought to understand the transformations that occurred not in the sense of physical modifications, but rather from a historical perspective of a process of conquest and occupation of a territory through an old road, which formed part of what is currently referred to as droving landscape.

According to [1], droving was an economic cycle that left marks in the past, and built an environment that formed the current notion of a droving landscape, which needs to be understood in contemporary times. Thus, we sought to understand human conduct in the past by analyzing maps and their spatial relations in the present, combining logic, perception and cognition in the same geographical and timeless space. It is important to preserve this cultural identity, because Brazil is a new Country, with little more than 500 years of the history. When preserving the landscape, human subjective factors must be taken into account and how much one wishes to maintain the preserved environment for the future. At this moment, it is important to considerate the human visual acuity.

As far as human visual acuity is concerned, [2] argued that some factors inherent in nature may interfere with the correct capture and perception of images by humans. The greater the amount of light and the shorter the viewing distance, the better the image will be formed, the lesser the influence of atmospheric effects and their consequent changes in radiation velocity, wavelength, intensity and spectral distribution. One of the phenomena that most interferes with 
image capture and perception is atmospheric refraction. Another factor that must be considered is earth curvature. It is necessary to consider both factors in analyses that evolve the landscape.

According to [5], earth curvature and the different densities in the atmosphere layers affect observations, especially with high viewing angles. It can be said that there are three distinct horizons for each point on the earth's surface. To reduce the effects of curvature and atmospheric refraction, Gaussian refraction coefficient was used. Details of the development of the equation can be seen in [6].

According to [2], visual perception can be described through logical phenomena, provided that some criteria are taken into account, such as scale, location, height of observation, logical schemes and etc.

According to [7], visual perception is a process of reconstruction of outer reality, carried out by the cerebral cortex, based on fragmented information captured by the eyes. Through the optic nerve that leads the nerve impulses to the cerebral cortex, located in the occipital region, a mental image is formed and the third dimension is recovered.

According to [8], Visual Acuity (VA) is the ability to discriminate the details of objects in the field of view, determined by the minimum dimension of some spatial aspects of visual stimuli, referring to the spatial limit of visual discrimination.

In quantitative and measurable terms, visual acuity refers to the subject's ability to detect, separate or discriminate an object in space. These capabilities correspond, respectively, to the smallest detectable object (detection acuity), the shortest distance between two objects for them to be detected as separate objects (separation or resolution acuity) and the smallest discriminable or recognized object (discrimination or recognition acuity) [8].

According to the [8], acuity can also be understood as being a characteristic of the eye to recognize two very close points either as the clarity or sharpness of the eyesight or the ability of the eyes to see fine details. In simple terms, acuity is the clarity of view of details and is divided into qualitative (ability to see objects close together) and quantitative (reciprocal angular value of separation between two neighboring objects that the eyes can see apart).

For quantification of acuity, the stimulus of visual perception of the human eye is nonlinear. For this reason, the Weber-Fechner Law was established, which is based on a logarithmic model of subjective perception of stimuli, for which only differences in brightness are noticeable [7], as shown in Figure 1.

Based on this law, [2] determined that human visual acuity is proportional to the logarithm of stimulus intensity, and this stimulus must grow exponentially so that human sight can differentiate it with increased distance from the object being observed. Some of our senses operate logarithmically, which makes the use of logarithmic scales appropriate for determining distances, what allowed the development of the method presented in this research, relating human visual acuity and the distances that objects could be inserted in the landscape, without carrying out concrete interventions in the region. 


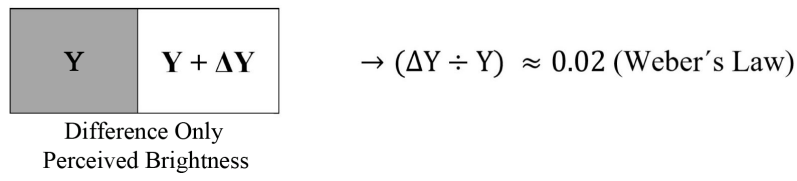

Figure 1. Weber's law.

In physical terms, normal (human) visual acuity is expressed as $20 / 20$, which indicates that a person can see at 20 feet (approximately $6.1 \mathrm{~m}$ ) what normally has to be seen at this distance. Visual acuity is influenced by brightness, color and contrast, and it can be measured using Snellen charts, which are widely used by ophthalmologists. The Snellen chart is a diagram used to evaluate a person's visual acuity; it was developed in 1862 by Dutch ophthalmologist Herman Snellen.

Humans see objects in a predefined visual field, which corresponds to the total area or visible space in peripheral vision with the eye looking straight ahead. Average length is approximately $65^{\circ}$ up, $75^{\circ}$ down, $60^{\circ}$ in and $95^{\circ}$ out. The human binocular visual field is approximately $124^{\circ}$. Visual fields can be measured by perimetry and can be analogous to the visual axes used in mapping.

\section{Study Area}

Coxilha Rica is an important region in the municipality of Lages, in the state of Santa Catarina/Brazil. It extends over an area around $800 \mathrm{~km}^{2}$. It stands out for its natural beauty and rich architectural heritage (see Figure 2). Important land transport routes crossed through Coxilha Rica, called Caminhos das Tropas ("Drovers' Paths"). They were built by the Portuguese crown in the eighteenth and nineteenth centuries with different objectives, for example:

- To prevent the Spanish attack and their permanent incursions into Portuguese territory, resulting from dissatisfaction with the Treaty of Madrid of 1750 ;

- To populate the backcountry, aiming at the expansion of Portuguese borders;

- To connect the backcountry of Colonial Brazil to the main villages of the empire, promoting economic integration and cultural exchange;

- To enable land communication among the Captaincies;

- To establish a regular and safe path to transport drovers, animals and goods to supply the internal market.

The main reason for the creation of these corridors was to facilitate transportation and avoid the dispersal of animals, which were mostly mules. The domestic market needed a supply of goods and Minas Gerais state needed strong and resilient animals to transport gold. Horses did not adapt to the rugged terrain and were automatically replaced by mules, because they are more resilient, withstand heavy loads and travel well on difficult terrains over long distances.

In the following centuries, during the coffee cycle, mule trains were also used. Over time, several branches were created. The route was generally determined by the conditions of the terrain, the march of the animals and the places of 


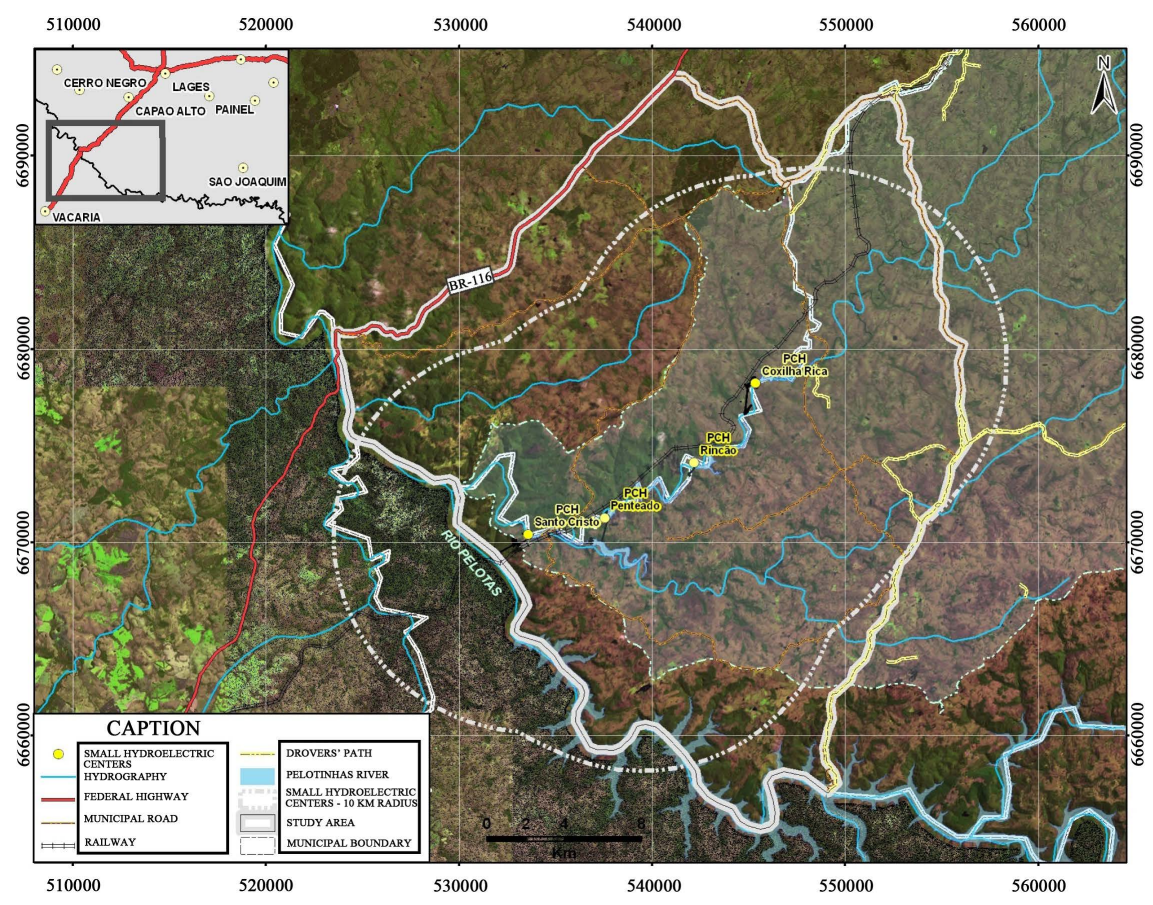

Figure 2. Study area.

pasture, water and stays. Along the Path, stations were created for such stays, determining the settlement of these sites, either through the construction of farms or commercial establishments. Stays sometimes lasted many months, because drovers needed to gain weight and recover physically, because they felt very weak as a result of the distance and the challenges posed by the journey. Also, drovers had to wait for the level of the rivers to go down so that they could cross the animals over more safely.

The construction of the first roads and farms usually used slave labor and was sponsored by landowners. The ground was stony, mostly made of basalt stones. Then, for greater safety and lesser impact on the drovers' journey, the stones were collected from the ground and used as the raw material for the construction of stone-walled corridors. They were laid tight together, eliminating the need for any kind of mortar joints (Figure 3).

The construction of the first roads and farms usually used slave labor and was sponsored by landowners. The ground was stony, mostly made of basalt stones. Then, for greater safety and lesser impact on the drovers' journey, the stones were collected from the ground and used as the raw material for the construction of stone-walled corridors. They were laid tight together, eliminating the need for any kind of mortar joints (Figure 3).

In Coxilha Rica, many of these stone-walled corridors are still preserved, and so are many farms over 100 years old, which eventually created a set of historical, cultural, architectural and landscape remnants, nonexistent in other regions of Brazil where animal drovers were also present. Many parts of these paths and farms are still in a good state of conservation and deserve to be preserved. 


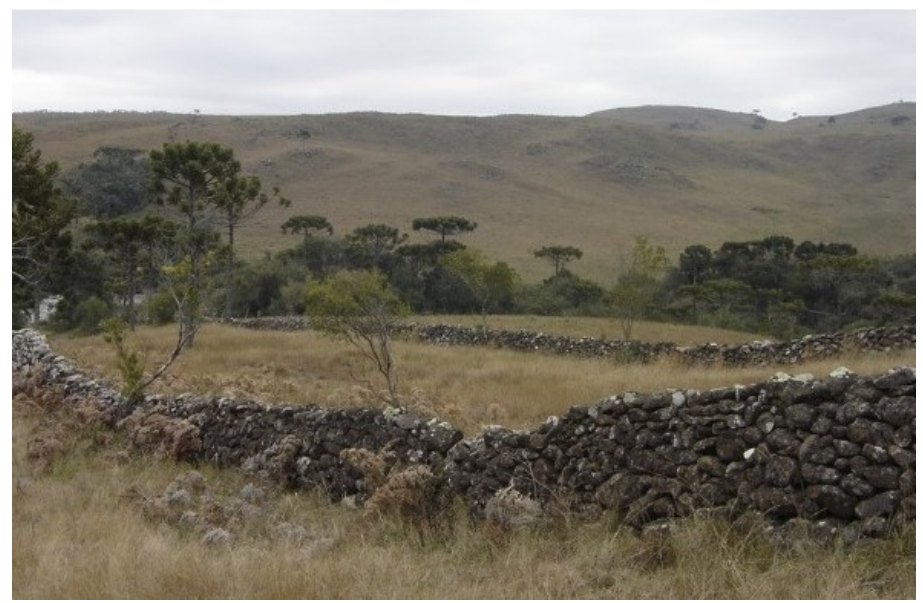

Figure 3. Stone-walled corridors.

\section{Materials and Methods}

This chapter describes the materials used to conduct the research, as well as the method to achieve the proposed objectives. The following materials were used:

- Official Cartographic Base of the State of Santa Catarina, 1:50,000 scale updated by the Environment Institute (IMA);

- Leica Tr405 total station;

- Panasonic RR Recorder, US510;

- Sony H9 Camera;

- Aster Digital Elevation Model (MDE) with planimetric resolution of $30 \mathrm{~m}$ and altimetric resolution of $20 \mathrm{~m}$;

- TOPCON Ryper Global Navigation Satellite System (GNSS) signal receiver;

- Trimble Juno Global Positioning System (GPS) signal receiver;

- Software: ArcGIS 3D Analyst Extension; AutoCad; GPS Pathfinder Office Topcon Tools and PC-CDU.

The main starting point to develop the method was, in principle, to define a value for human linear visual acuity (Ai), taking into consideration a $24 \mathrm{~m}$ high power transmission tower, was defined as the object of study, and then delimit the area of visibility of the observer. Logarithmic scales and adaptations of the Snellen table with a horizontal distance of $6 \mathrm{~m}$ were used. Horizontal distances between the observer and the transmission tower were determined. The height of the tower was reduced, for each distance, by lowering the Gauss [6]:

$$
\begin{gathered}
\mathrm{Gi}=0.87 * \mathrm{Di} 2 / 2 \mathrm{R} \\
\mathrm{Hi}=\mathrm{HT}-\mathrm{Gi}
\end{gathered}
$$

where:

- $\mathrm{Gi}=$ lowering of Gauss;

- $\mathrm{Di}=$ horizontal distances between observer and transmission tower;

- $\mathrm{R}=$ (mean ellipsoidal radius of the Earth $)=6,370,000$ meters;

- $\mathrm{Hi}=$ reduced transmission tower height;

- HT (height of the transmission tower) $=24$ meters. 
Through trigonometric relations, the heights at the corresponding distances observed in the bulkhead were determined, resulting in the following equation:

$$
(\mathrm{DA} * \mathrm{Hi}) / \mathrm{Di}=\mathrm{hi}
$$

where:

- DA (horizontal distance from the bulkhead) $=6$ meters;

- $\mathrm{Hi}=$ vertical distance of visual acuity projected on the bulkhead.

The angular intervals for the height of the tower were also determined, in relation to the projection to the bulkhead, for each calculated distance, according to the following equation:

$$
\mathrm{a}=\operatorname{tg}(\mathrm{Hi} / \mathrm{Di})
$$

Visual acuity was used as the tangent angle formed by the distance from the bulkhead and the vertical distance of the human visual acuity projected on the bulkhead, so that the value returned was compatible with the linear acuity, relative to the established limit of one minute of degree (1'):

$$
\mathrm{DA} * \operatorname{arctgb}=\mathrm{Ai}
$$

where:

- $\mathrm{b}$ (angular acuity) $=0^{\circ} 01^{\prime} 00^{\prime \prime}$ or $0.016667^{\circ}$;

- $\mathrm{Ai}$ (linear acuity) $=0.0144$ meters.

After determining the new height perceived by the view of the tower, the respective height projected on the bulkhead was calculated. The determination of a bulk-head was necessary to establish the trigonometric relationships between the observer, visual acuity and the projection of the tower's view on the bulkhead.

After applying the formulas was shown that, from a distance of $8100 \mathrm{~m}$, the projection of the tower's view on the bulkhead is less than the deter-mined value of $0.0144 \mathrm{~m}$, meaning that, from this distance, the vision loses sharp-ness and the tower is no longer perceived by the observer.

Thus, the remainder of the method consisted of generating reproducible criteria on how to map the visibility spot reached from the main points chosen to the limit of $8100 \mathrm{~m}$ that involved the following procedures:

- Cartographic and iconographic documentary research and land ownership documents, bibliographical references, among others;

- Interviews with owners, researchers and people with knowledge of the history of the region;

- Surveys of historical registers;

- Cartographic modeling and generalization of register data;

- Identification of significant points (animal drovers' paths and historical farms);

- Analysis and definition of procedures for generation of visibility polygons: quantitative geometric and qualitative thematic analyses;

- Generation of single and multiple visibility polygons from farms and stonewalled corridors;

- Evaluation of thematic quality through photographic and videographic control and quantitative evaluation using topography; 
- Generation of Visibility Polygons through matrix weighting;

- Determination of the weights of the information levels;

- Generation of visibility polygon maps at different scales.

\section{Results and Analysis}

The results presented that, at a distance of $8100 \mathrm{~m}$ or further, the projection of the view of a $24 \mathrm{~m}$ tower in the shield is smaller than the determined value of $0.0144 \mathrm{~m}$ (linear acuity), then all analyzes were restricted to $8100 \mathrm{~m}$ from the reference points

The historical, bibliographic and field research followed the criteria previously established by IPHAN and, together with the topographic survey, it enabled the identification, characterization and mapping of historical farms and animal drovers' paths, with proper data from the Brazilian Geodetic System (BGS). The information collected was sufficient to meet IPHAN criteria and produce the following results:

- Characterization and description of historic farms and stone-walled corridors, including historical and photographic survey;

- Floor plans, sketches of location and implementation of farms;

- Register survey of historic farms: main house, corral enclosures and other facilities, on a 1:2000 scale;

- Topographic survey of corridors: central axis on a 1:10,000 scale.

Starting at the main house of the historical farms (see example in Figure 4), reference points (see Figure 5) were determined in the field, which allowed the generation of visibility polygons for each case. The reference point was carefully defined: prominent position, rising, near the main house, with a good view of the surroundings and representative of each farm.

After data processing (for each farm and each quadrant), the resulting information was input into the cartographic database to cross-check the data and analyze the visibility of the surrounding farms and stone-walled corridors together. See Figure 6, a example for the first quadrant (between $0^{\circ}$ to $90^{\circ}$ ) of the Santa Cecília Farm.

During the development of the method, several analyses and simulations were performed in a Geographic Information System (GIS) through the tool "Viewshed" of the software ArcGIS. The DEM model, as used in ASTER analyses, allowed the presentation scale to be compatible with the 1:50.000 scale.

The same criterion was applied for the definition of the reference lines for the drovers' paths; a simulation was made of an observer walking over the stonewalled corridor in a certain stretch of the path, resulting in a different visibility area for each point walked over.

After applying the method in a computational environment and generating the visibility areas of each point, the method was validated by photographic and videometric survey at $360^{\circ}$ of the surrounding area from the same data collection points. 


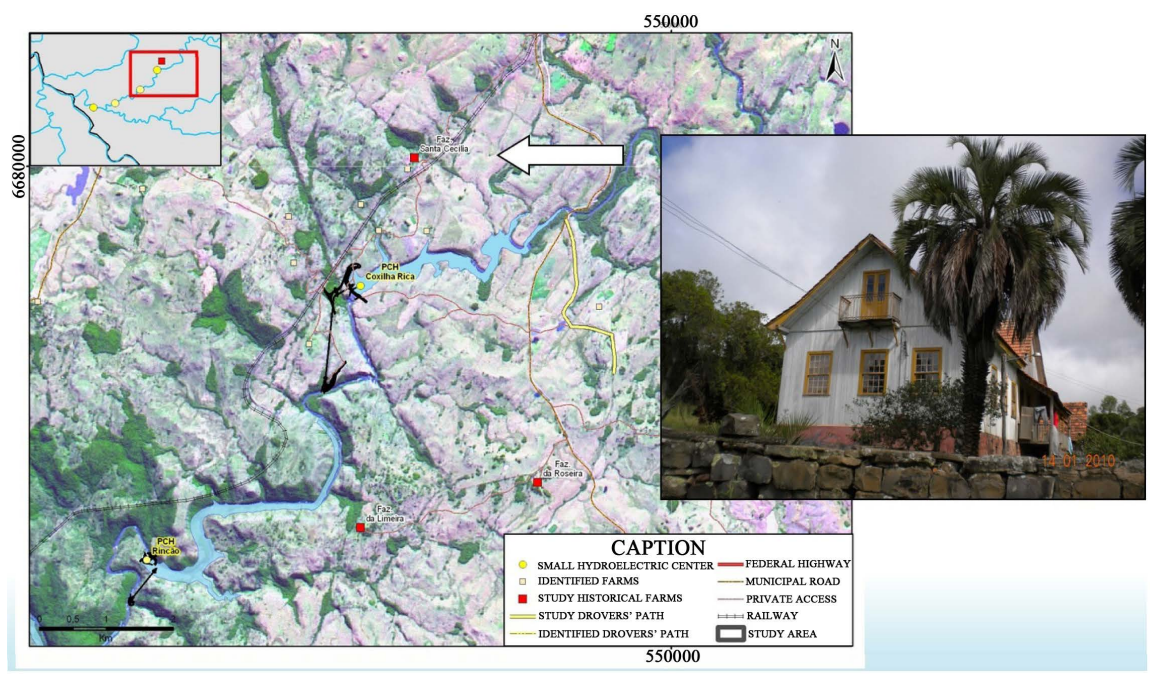

Figure 4. Location and main house of Santa Cecilia farm.

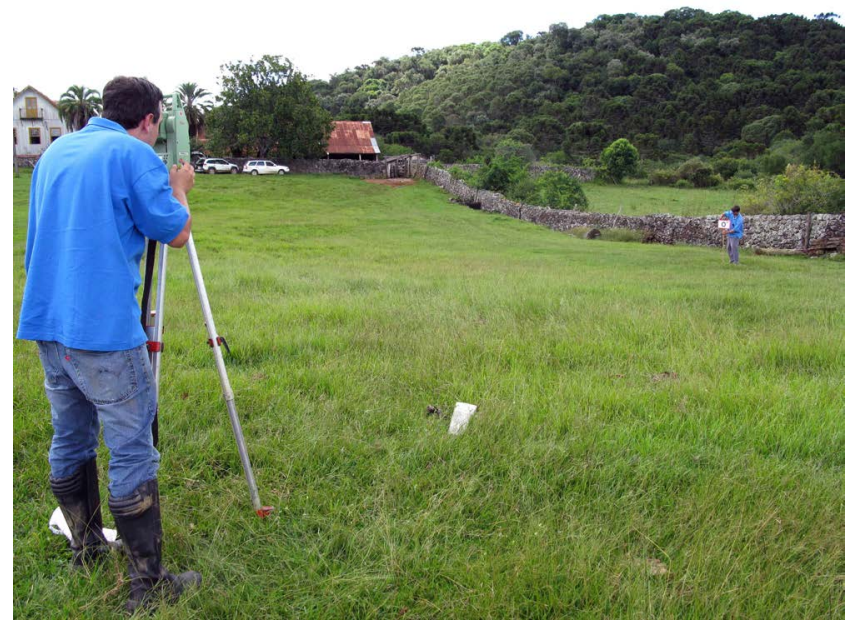

Figure 5. Reference pointo for Santa Cecilia farm.

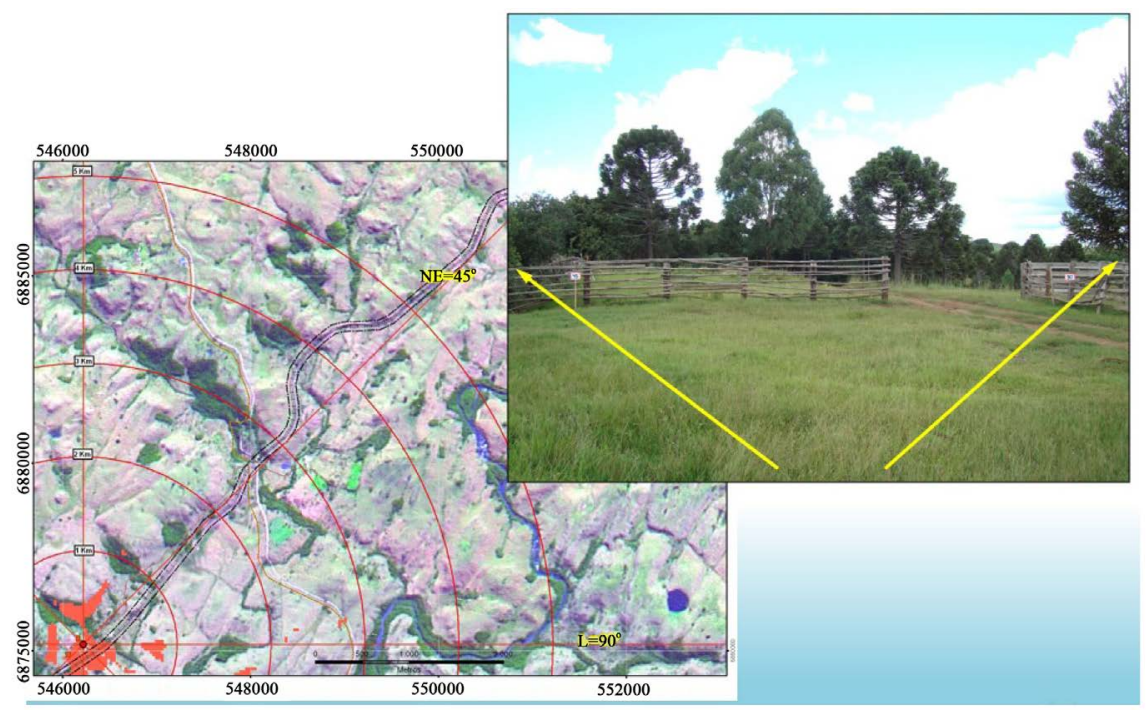

Figure 6. Poligonal visibility for the first quadrant of the Santa Cecilia farm. 
The validation process consisted of installing a Total Station just above the reference point of the farm or corridor (see Figure 5), and then fixing beacons and flags identified at every $45^{\circ}$ within a radius of 15 meters, making a $360^{\circ}$ circle. The reference used to support the survey was the northern grid of the Universal Transverse Mercator (UTM) projection. After the survey of the coordinates of each flag through the Total Station, a camera was installed at the same point for taking photographs and making videos. With the camera resting on the reference point, photographs and footage were captured on the same $360^{\circ}$ radius with proper identification of the beacons and flags every $45^{\circ}$ (see Figure 7). The parameters considered in the field in the method validation were the same as those used in the GIS environment; the footage and photographs were used to compare the simulation results and perform detailed analyses.

Figure 7 shows the validation scheme of the method for the generation of visibility polygons. The center of the target (red circles) corresponds to the reference point of Figure 7 , and the flags at every $45^{\circ}$ are represented in eight sectors: $\mathrm{N}=0^{\circ} ; \mathrm{NE}=45^{\circ} ; \mathrm{E}=90^{\circ} ; \mathrm{SE}=135^{\circ} ; \mathrm{S}=180^{\circ} ; \mathrm{SW}=225^{\circ} ; \mathrm{W}=270^{\circ}$ and $\mathrm{NW}=315^{\circ}$. The scheme also shows the radii of distance from the reference point ranging from 1 to $15 \mathrm{~km}$ (in Figure 7) and from 1 to $8 \mathrm{~km}$ (in Figure 8).

The red spots on the surface of the terrain (Figure 7) are the visibility polygons generated by geoprocessing techniques with the "Viewshed" tool of software ArcGIS. When compared to the field footage and photographs, they allowed the analysis of each sector separately and also enabled the observation and identification of elements not represented by the DEM. These elements correspond mostly to the vegetation and buildings that exist around the reference points and which represent an obstacle to the horizon view. However, the results

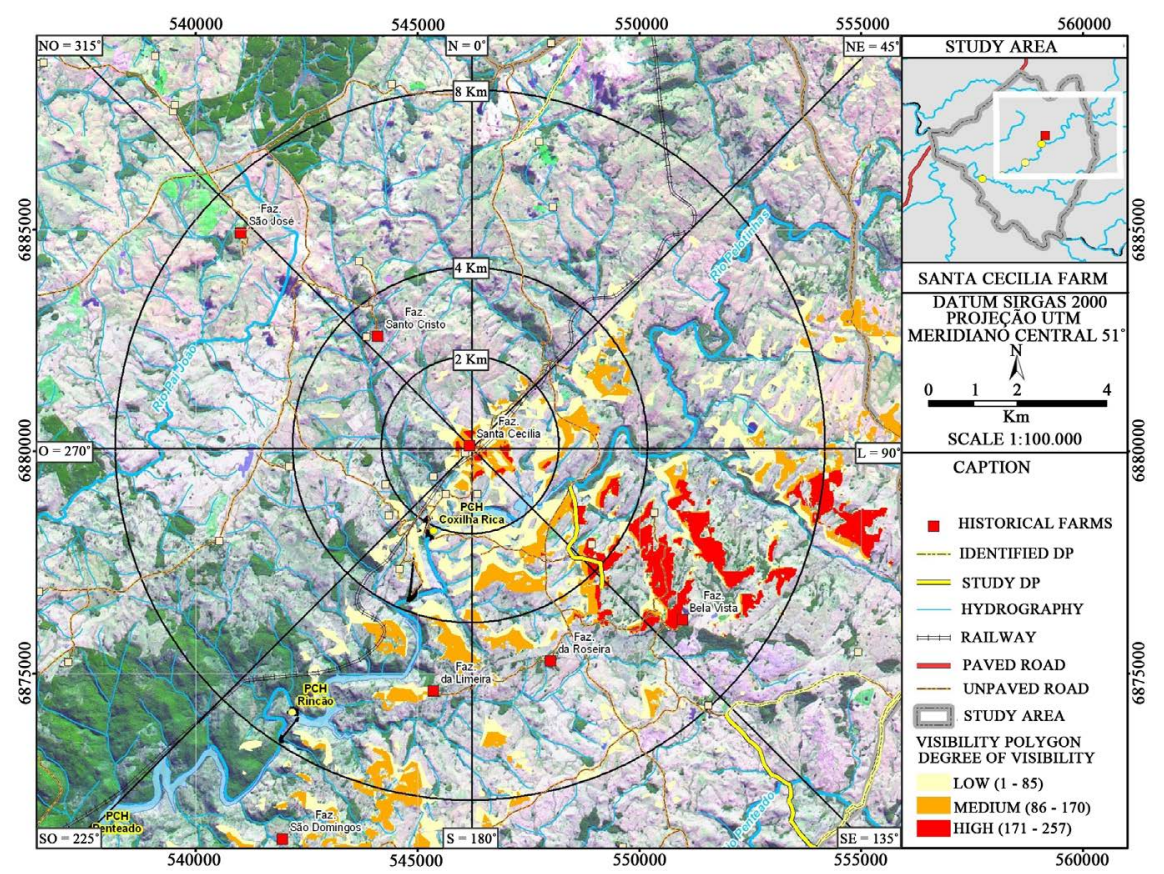

Figure 7. Method validation Scheme. 


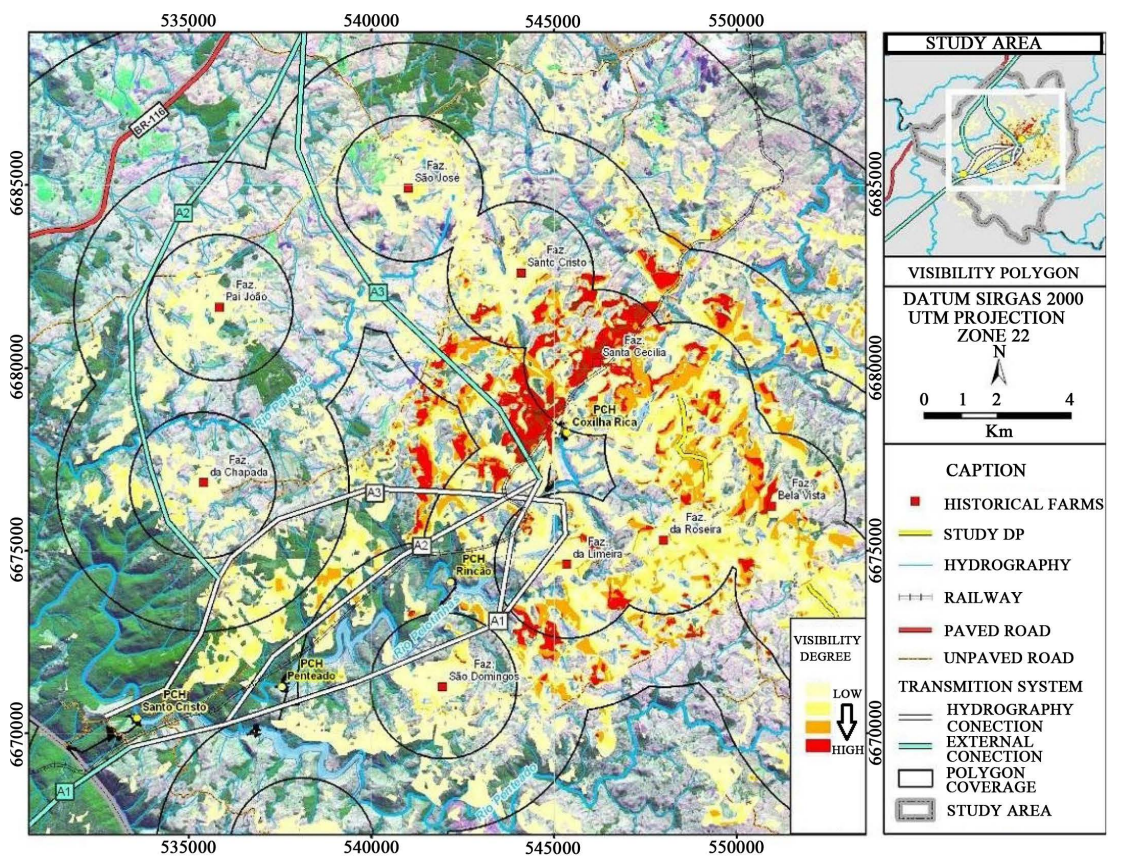

Figure 8. Visibility polygon of Santa Cecilia farm.

seen in the visibility polygons indicate visibility beyond those obstacles. Thus, we could define the limitations of the method that are inherent in the precision and generalization of the DEM.

The visibility polygons of each farm or stone-walled corridor were classified by degree of visibility into three class ranges: low, medium and high (see Figure 9). To determine the weights, the hierarchical weighting method was used, in which the high degree of visibility was related to the largest number of areas (pixels) that are viewed from the observer's point of view. The map of the visibility polygon of Santa Cecília Farm and the stone-walled corridors near the farm (Figure 8), show that the polygon classified as having low visibility is viewed by between 1 and 86 observers (points) from, or on, Santa Cecília Farm (dot) or the stone-walled corridor (lines) highlighted in yellow. The polygon classified as having medium visibility is viewed by between 86 and 170 observers and the polygon with high visibility is observed by between 171 and 259 observers.

After the development of each map (from each farm and from each stonewalled corridor), an integrated analysis of the visibility polygons was performed, resulting in a main map showing the degree of visibility of the study area (see Figure 9). In total, polygons were integrated and analyzed from 10 historic farms and 04 sections of stone-walled corridors).

After the generation of the visibility polygon of the drovers' paths (stonewalled corridors) and historical farms, tracing alternatives could be designed and evaluated for the hydroelectric transmission system, considering towers with a height of $24 \mathrm{~m}$ (Figure 9), in order to minimize the visual impact caused by the increase of metallic structures in the scenic environment of the landscape. 


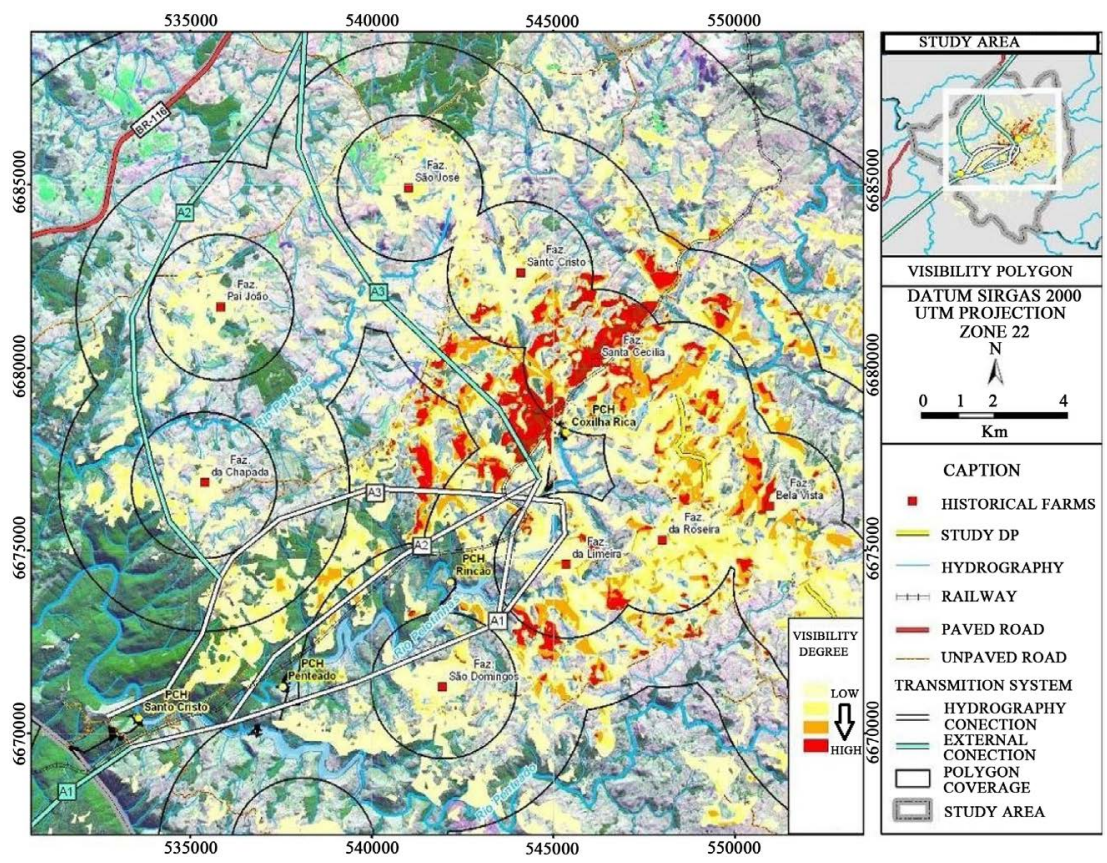

Figure 9. Integrated analysis of visibility polygons.

The entities involved, after considering all the results and analyzes, made the decision not to build the transmission systems and preserve the scenic environment of the Coxilha Rica region.

\section{Final Remarks}

In conclusion, all objectives were achieved, since was determined the maximum radius of virtual range that was considered in the generation of visibility polygons, taking human visual acuity into consideration.

By obtaining the visibility polygons generated from each historical farm or each segment of the stone-walled corridors, and using cartographic tools, we could cross-check information levels, classify and define the degree of visibility of the final polygon, thus enabling territorial management in the landscape of Coxilha Rica.

Based on the final visibility polygon, energy entrepreneurs were able to design their energy transmission systems and verify that the impact would be very large and decided not to build their systems in the Coxilha Rica region.

The method developed in this research provided IPHAN with information to define the best locations for future interventions, generate visibility polygons for various purposes, and geographically identify the farms and historical paths of the Coxilha Rica region.

It is also concluded that the method is universally applicable because it can be applied to any geographic region

\section{Acknowledgements}

We would like to thank Eletrosul for allowing the publication of the data in this 
paper.

\section{Conflicts of Interest}

The authors declare no conflicts of interest regarding the publication of this paper.

\section{References}

[1] Abati, S., Celestino, V.S. and Kunz, R. (2010) Complexo de PCH do rio pelotinhas estudo de visibilidade: análise de intervenção na paisagem. Trabalho Técnico, Eletrosul, Florianópolis.

[2] Celestino, V.S. (2017) Estimativa de alcance visual humano aplicado à preservação de ambientes cênicos. Revista de Geografia e Ordenamento do Território, 11, 99-123. https://doi.org/10.17127/got/2017.11.005

[3] UNESCO (1999). Convenção do Patrimônio Mundial. Cartas Patrimoniais, Instituto do Patrimônio Histórico e Arqueológico Nacional (IPHAN), Brasil.

[4] Herberts, A.L. (2009) Arqueologia do Caminho das Tropas: Estudo das estruturas viárias remanescentes entre os rios Pelotas e Canoas, SC. Ph.D. Thesis, Pontifícia Universidade Católica do Rio Grande do Sul (PUCRS), Porto Alegre.

[5] Silva, J.L. (2010) Nivelamento Trigonométrico. Apostila, Universidade Federal do Rio Grande do Sul (UFRGS), Porto Alegre.

[6] Espartel, L. (1965) Curso de Topografia. Editora Globo, Porto Alegre.

[7] Stolfi, G. (2008) Percepção Visual Humana. Televisão Digital, 4, 1-13.

[8] Carmona, F.M.M., Costa, M.F., Ventura, D.F., Salomão, S.R. and Barros, P.S.M. (2006) Acuidade visual de resolução de grades pelo método dos potenciais visuais evocados de varredura: padronização da metodologia para uso em cães. Brazilian Journal of Veterinary Research and Animal Science, 43, 86-92.

https://doi.org/10.11606/issn.1678-4456.bjvras.2006.26540 